\title{
THE THANKSGIVING MEETING IN LEXINGTON
}

The three hundred twenty-sixth regular meeting of the Society was held at the University of Kentucky on Friday and Saturday, November 29-30, 1935. About ninety persons attended, among whom were the following thirty-two members of the Society:

N. B. Allison, B. M. Armstrong, F. R. Bamforth, I. A. Barnett, W. D. Baten, Henry Blumberg, P. P. Boyd, W. S. Claytor, L. W. Cohen, L. L. Dines, H. H. Downing, K. W. Folley, Harris Hancock, E. H. Hanson, M. H. Ingraham, E. D. Jenkins, C. G. Latimer, F. E. LeStourgeon, C. W. Mendel, H. A. Meyer, C. N. Moore, David Moskovitz, A. L. Nelson, E. G. Olds, R. S. Park, E. D. Pepper, R. F. Rinehart, J. B. Rosenbach, W. F. Smith, Guy Stevenson, J. J. Stoker, J. M. Thomas.

Friday afternoon Professor C. G. Latimer of the University of Kentucky gave an address entitled The arithmetic of generalized quaternions, and on Saturday afternoon Professor L. L. Dines of Carnegie Institute of Technology spoke on Convex domains and linear inequalities.

Friday afternoon the mathematicians and their guests attended a very enjoyable tea at the home of President and Mrs. McVey.

A dinner was held at the Lafayette Hotel Friday evening. Sixty mathematicians and their guests attended. The toastmaster, Dean P. P. Boyd of the University of Kentucky, called first upon President McVey who extended to the group a welcome to the University. A response was given by Professor C. N. Moore of the University of Cincinnati. Professor J. M. Thomas of Duke University spoke about his experiences as Managing Editor of the new Duke Mathematical Journal during its first year, and the policies and future of the Journal. Short talks were then given by Professors M. H. Ingraham of the University of Wisconsin, Harris Hancock of the University of Cincinnati, C. G. Latimer of the University of Kentucky, and L. L. Dines of the Carnegie Institute of Technology.

At the session on Saturday afternoon a resolution was passed thanking the President and Trustees of the University of Kentucky and the Department of Mathematics for their hospitality. 
Friday afternoon Professor Blumberg presided. Professors Downing and Moore presided Saturday morning and afternoon respectively.

The titles of papers read at the meeting follow. Mr. Haim Reingold was introduced by Professor I. A. Barnett, Mr. P. M. Pepper by Professor Harris Hancock, and Professor Fritz John by Professor C. G. Latimer. Those abstracts numbered 1 to 3 were presented Friday afternoon; those numbered 4 to 9 , Saturday morning; and those numbered 10 through 20 were read by title on Saturday morning.

1. Generalized determinants of Vandermonde. II, by Mr. Haim Reingold. (Abstract No. 41-11-400.)

2. Frequency distributions of means of $n$ independent variables whose frequency distributions can be dissected into component frequency laws, by Professor W. D. Baten. (Abstract No. 41-11396.)

3. On necessary and sufficient conditions for convergence factors in multiple series, by Professor C. N. Moore. (Abstract No. 4111-394.)

4. Cauchy convergence in topological space (preliminary report), by Professor L. W. Cohen. (Abstract No. 41-11-399.)

5. Minkowski's geometry of numbers, by Professor Harris Hancock. (Abstract No. 42-1-67.)

6. Application of the geometry of numbers to a generalization of continued fractions, by Mr. P. M. Pepper. (Abstract No. 42-1-3.)

7. Some properties of the discriminant matrices of a linear associative algebra, by Professor R. F. Rinehart. (Abstract No. 4111-389.)

8. On the moments of inertia of convex regions. II, by Professor Fritz John. (Abstract No. 41-11-402.)

9. The form of surfaces of positive curvature in three-dimensional space, by Professor J. J. Stoker, Jr. (Abstract No. 41-11-393.)

10. Two notable classes of hypersurfaces, by Professor Arnold Emch. (Abstract No. 41-11-388-t.)

11. Note on the history of elliptic functions, by Professor Tobias Dantzig. (Abstract No. 41-11-405-t.)

12. A note on Young-Stieltjes integrals, by Dr. F. G. Dressel. (Abstract No. 41-11-382-t.)

13. Involutorial space transformations associated with a ra- 
tional ruled surface. II, by Professor L. A. Dye. (Abstract No. 41-11-387-t.)

14. On certain factorial sums, by Dr. Solomon Kullback. (Abstract No. 41-11-392-t.)

15. Note on a problem of E. Čech, by Dr. Leo Zippin. (Abstract No. 41-11-390-t.)

16. On monotonic, complete covering systems, by Dr. Leo Zippin. (Abstract No. 41-11-391-t.)

17. A recursion formula for the polynomial solutions of differential equations with constant coefficients, by Professor C. C. MacDuffee. (Abstract No. 41-11-395-t.)

18. A new method for Waring theorems with polynomial summands. II, by Professor L. E. Dickson. (Abstract No. 41-11397-t.)

19. Abstract vector spaces of uncountably many dimensions, by Dr. C. W. Vickery. (Abstract No. 41-11-398-t.)

20. On the moments of inertia of convex regions. I, by Professor Fritz John. (Abstract No. 41-11-401-t.)

M. H. INGRAHAM, Associate Secretary 